\title{
REPRESENTAÇÕES SOCIAIS ACERCA DOS RISCOS DE ACIDENTES DE TRABALHO
}

\section{Social representations of occupational accident risks \\ Representaciones sociales sobre los riesgos de accidentes de trabajo}

\author{
Pablo Luiz Santos Couto \\ Centro de Ensino Superior de Guanambi - CESG - Guanambi (BA) - Brasil
}

\section{Andréia Cristina Gomes}

Centro de Ensino Superior de Guanambi - CESG - Guanambi (BA) - Brasil

\section{Fernanda Fernandes Alves}

Centro de Ensino Superior de Guanambi - CESG - Guanambi (BA) - Brasil

\section{Edmar Castelan}

Pontifícia Universidade Católica de Minas Gerais - PUC/MINAS - Belo Horizonte (MG) - Brasil

\section{Rachel Verdan Dib}

Universidade do Estado do Rio de Janeiro - UERJ - Rio de Janeiro (RJ) - Brasil

Magno Conceição da Mercês

Universidade do Estado da Bahia - UNEB - Salvador (BA) - Brasil

\section{Antônio Marcos Tosoli Gomes}

Universidade do Estado do Rio de Janeiro - UERJ - Rio de Janeiro (RJ) - Brasil

\section{RESUMO}

Objetivo: Analisar as representações sociais de profissionais de enfermagem acerca dos riscos de acidentes de trabalho. Métodos: Estudo do tipo qualitativo, com eixo teórico na teoria das representações sociais, realizado com 70 profissionais de enfermagem (enfermeiros e técnicos) em regime de plantão noturno em um Hospital Regional do Município de Guanambi, Bahia, Brasil, no período de março e abril de 2017. Utilizou-se como técnica de coleta de dados a associação livre de palavras e a entrevista em profundidade. As evocações foram analisadas mediante a análise de conteúdo. Resultados: As palavras evocadas pelos entrevistados, com maior significação e frequência, para o termo indutor riscos ocupacionais, foram: acidente, segurança e bactéria. Para o outro termo indutor, riscos biológicos, foram: sangue, bactéria, secreção e contaminação. As representações sociais acerca dos riscos de acidentes de trabalho demonstram que o conhecimento científico é difundido no grupo, reforçando o quanto o assunto faz parte do cotidiano de trabalho, uma vez que é propagado e compartilhado entre eles. Os participantes representam os riscos e os acidentes como algo distante de suas realidades laborais, ou seja, pensam que não correm o risco de se contaminarem ou de sofrerem outro tipo de acidente. Conclusão: Os resultados demonstraram, através das representações sociais, que os profissionais de enfermagem sabem da existência dos riscos para os acidentes de trabalho, como os riscos ocupacionais e os riscos biológicos, reconhecendo o perigo, mas com o outro, não consigo, o que sugere uma dificuldade em distinguir a própria insegurança.

Descritores: Saúde do Trabalhador; Acidentes de Trabalho; Enfermagem.

\section{ABSTRACT}

Objective: To analyze nursing professionals' social representations of occupational accident risks. Methods: Qualitative study based on the social representations theory carried out with 70 nursing professionals (nurses and technicians) on night duty at a Regional Hospital in the Municipality of Guanambi, Bahia, Brazil, from march to April 2017. Free association of words and in-depth interviews were used to collect data. Results: The most significant and frequent words used to refer to occupational risks were: accident, safety and bacteria. Biological risks were referred to using the words: blood, bacteria, secretion and contamination. The social representations of occupational accident risks show that scientific knowledge is disseminated in the group, reinforcing how much the subject is part of the daily work, as it is spread and shared among them. The participants represent risks and accidents as something far from their labor reality, that is, they think that they are not at risk of becoming contaminated or suffering another type of accident. Conclusion: The results demonstrated, through the social representations, that nursing professionals know about the existence of occupational accident risks, such as occupational risks and biological risks, and recognize that other people, and not themselves, are at danger, which suggests a difficulty in recognizing their own insecurity.

Descriptors: Occupational Health; Accidents, Occupational; Nursing. 


\section{RESUMEN}

Objetivo: Analizar las representaciones sociales de profesionales de enfermería sobre los riesgos de accidentes de trabajo. Métodos: Estudio cualitativo con eje teórico en la teoría de las representaciones sociales realizado con 70 profesionales de enfermería (enfermeros y técnicos) de un Hospital Regional del Municipio de Guanambi, Bahia, Brasil, en régimen de guardia nocturno en el periodo entre marzo y abril de 2017. Se utilizó como técnica para la recogida de datos la asociación libre de palabras y la entrevista en profundidad. Se analizaron las evocaciones a través del análisis de contenido. Resultados: Las palabras evocadas por los entrevistados con más significación y frecuencia para el término "inductor riesgos ocupacionales" fueron: accidente, seguridad y bacteria. Para el otro término "inductor riesgos biológicos" las palabras fueron sangre, bacteria, secreción y contaminación. Las representaciones sociales sobre los riesgos de accidentes de trabajo demuestran que el conocimiento científico está difundido en el grupo lo que refuerza cuánto el tema hace parte del cotidiano de trabajo una vez que es propagado y compartido entre ellos. Los participantes representan los riesgos y los accidentes como algo lejano de sus realidades laborales, o sea, piensan que no tienen riesgo de contaminación o de otro tipo de accidente. Conclusión: A través de las representaciones sociales los resultados demuestran que los profesionales de enfermería saben de los riesgos para los accidentes de trabajo como los riesgos ocupacionales y los biológicos reconociendo el peligro pero con el otro y no con uno mismo lo que sugiere una dificultad para distinguir la propia inseguridad.

Descriptores: Salud Laboral; Accidentes de Trabajo; Enfermaría.

\section{INTRODUÇÃO}

Os acidentes de trabalho (AT) têm se tornado constante no ambiente laboral dos trabalhadores de diversas categorias profissionais, dentre os quais se incluem os envolvidos com a saúde, por estarem expostos à inúmeros riscos, sobretudo os biológicos ${ }^{(1)}$. Em decorrência do aumento das práticas preventivas e da obrigatoriedade do uso de equipamentos de proteção individual (EPI), as taxas de mortes têm sido mínimas ${ }^{(2,3)}$.

Os AT podem ser conceituados como eventos, contudo, estão além de ser acidentais ou fortuitos. Eles são fenômenos sociais, determinados e previsíveis, além de serem preveníveis. Ocorrem na prática das atividades laborais que acarretam possíveis danos à saúde ${ }^{(4,5)}$. No cotidiano de trabalho, esses acidentes podem ser constantes, em decorrência do contato com material perfurocortante ${ }^{(6)}$.

No mundo, $60 \%$ dos profissionais de enfermagem, os quais correspondem a 33\% da força de trabalho hospitalar, são afetados por lesões ou outros tipos de desordens ocupacionais ${ }^{(7)}$. Na China, no Japão e em Taiwan, os profissionais de enfermagem têm a cefaleia como principal agravo ocupacional, com taxas que variam de 40,9\% a 49,6\% entre os três países ${ }^{(8)}$. Por sua vez, em todo o Brasil, a maior parte dos agravos sofridos pelos profissionais de enfermagem são decorrentes de acidentes com agulhas $(68,2 \%)^{(9)}$. Em um estudo realizado com trabalhadores de enfermagem em um hospital público no estado do Mato Grosso, Brasil, no ano de 2016, apontou altas taxas (46,3\%) de acidentes de trabalho com material perfurocortante entre os profissionais de enfermagem e, entre os acidentados, grande parte $(63,5 \%)$ relatou ter se acidentado duas vezes ${ }^{(10)}$.

Em se tratando do turno noturno, os AT e os riscos tornam-se potencializados, em decorrência da rotina desgastante, da perda de sono e do estado vigilância, como pode ser visto em estudo realizado nos Estados Unidos da América, no ano de 2011, com trabalhadores do turno noturno, especificamente com motoristas de caminhão. Evidenciou-se que o desenvolvimento de quaisquer atividades psicomotoras durante a noite aumenta risco de acidentes e lesões, uma vez que não houve uma compensação da sonolência durante a noite e a pressão homeostática elevada do sono interage com o pico da propensão do sono circadiano, o que leva a criação de uma vulnerabilidade crítica da zona de desempenho das atividades laborais ${ }^{(11)}$.

Os profissionais que atuam na área da saúde estão submetidos a diversos riscos determinantes de AT devido à contaminação e manipulação de materiais que contém micro-organismos, por isso, é importante que esses trabalhadores tenham conhecimento sobre as doenças e os agravos aos quais estão submetidos dentro do seu local de trabalho, podendo-lhes causar danos à saúde ${ }^{(4)}$.

De acordo com o artigo 19 da Lei no 8.213, de 24 de julho de 1991, existem dois tipos de acidentes de trabalho: o que ocorre durante a prestação de serviço e o que pode acontecer no trajeto à empresa. Nas duas formas diferentes, o AT pode ocasionar morte ou perda, possível trauma relacionado ao acidente, lesão corporal, causando uma redução na capacidade de desenvolver as atividades diárias. Sendo assim, é de responsabilidade da unidade ofertar equipamento de proteção individual (EPI) para o profissional conforme os riscos ao qual o mesmo está exposto ${ }^{(12)}$.

Tendo em vista que, dentre a equipe multidisciplinar da unidade hospitalar, os profissionais de enfermagem são os que estão mais expostos aos materiais biológicos, devido à manipulação de objetos perfurocortantes e materiais contaminados, poderão adquirir algum tipo de doença infecciosa, como o vírus da imunodeficiência humana (HIV), o vírus da hepatite B (HBV) e o vírus da hepatite $\mathrm{C}(\mathrm{HCV})^{(6)}$.

A notificação dos casos de acidentes de trabalho é importante para tomar decisões e ações preventivas adequadas. Contudo, sabe-se que há um índice elevado de subnotificação, pois, decorrente da falta de informação sobre sua importância ou até 
devido ao medo de demissão, alguns profissionais não se mostram conscientes dos riscos envolvidos, o que acaba levando a não notificação ${ }^{(6)}$.

Sendo assim, o Ministério do Trabalho, receoso com o leque de coisas que ligam as questões de saúde do trabalhador e doenças ocupacionais através de riscos biológicos, criou a Norma Regulamentadora (NR) 06 em 08 de junho de 1978, a Portaria $\mathrm{n}^{\mathrm{o}} 3.214$ e Norma Regulamentadora 32, de 11 de novembro de 2005, e a Portaria $\mathrm{n}^{\mathrm{o}} 485^{(13,14)}$.

A teoria das representações sociais (TRS) se adequa na transversalização com esse objeto por considerar a influência da comunicação na forma das representações, uma vez que são formadas pela troca, difusão e compartilhamento do conhecimento dentro do grupo de pertencimento, que, por sua vez, leva em conta a influência social para as construções de significações de fenômenos no cotidiano ${ }^{(15)}$.

Os serviços de saúde, de um modo geral, oferecem riscos de contaminação, pois são locais de baixa, média ou alta complexidade, onde são prestados cuidados assistenciais para todos os tipos de pessoas, além de serem permeados por uma variedade de fatores que contribuem e aumentam os riscos de acidentes com materiais biológicos. As medidas de biossegurança, como o uso de EPI, devem ser adotadas, uma vez que os riscos biológicos advém da complexidade dos serviços de saúde, como o tipo de atendimento ofertado, o ambiente de trabalho e os materiais com que entram em contato ${ }^{(16)}$.

Um estudo randomizado, realizado em três regiões da Holanda no ano de 2014, com trabalhadores da construção civil, traz recomendações acerca da prevenção de acidentes que corroboram com tais informações, uma vez que consideram que, para aumentar o cumprimento dos procedimentos de segurança, os empregadores e os trabalhadores precisam selecionar, implementar e monitorar medidas de segurança. Para facilitar essa mudança comportamental, deve-se estimular a conscientização do conhecimento e técnicas de mudança de comportamento. Além disso, treinamentos, ações educativas, a discussão de casos e assuntos cotidianos podem melhorar a segurança e a saúde ocupacional da força de trabalho ${ }^{(17)}$.

Ainda que exista a obrigação do uso de EPI para a diminuição dos riscos, os profissionais de enfermagem apresentam dificuldade e resistência para sua utilização ${ }^{(6)}$. Por isso, este estudo se justifica pela possibilidade de revelar, por meio das representações sociais, o conhecimento de profissionais de enfermagem sobre os riscos ocupacionais e, desse modo, revelar a importância que eles dão ao uso desses equipamentos durante suas atividades laborais. Este estudo também é relevante para a Saúde Coletiva por tangenciar o olhar para esse problema de saúde pública. Além disso, com o auxílio da TRS, há a possibilidade de refletir como os profissionais de enfermagem significam os acidentes ocupacionais no cotidiano de trabalho e, a partir disso, auxiliar na promoção à saúde ocupacional através de estratégias, como a educação em saúde.

Devido à exposição e possibilidade de acidentes de trabalho, além do risco para a contaminação por micro-organismos dentro da unidade de saúde, e das dificuldades em se trabalhar à noite, traçou-se como questão de pesquisa: Como a equipe de enfermagem do turno noturno representa os riscos de acidentes de trabalho na realização das atividades laborais? Para nortear a resposta a tal questionamento, objetivou-se analisar as representações sociais de profissionais de enfermagem acerca dos riscos de acidentes de trabalho.

\section{MÉTODOS}

Realizou-se um estudo qualitativo ${ }^{(18)}$ fundamentado na teoria das representações sociais ${ }^{(15)}$, definida por ser uma demonstração filosófica que consiste na formação de uma percepção anterior da realidade do conteúdo em pensamento. Tal estudo possui relação direta com as influências comunicativas que são criadas e configuradas a todo o momento, resultantes do equilíbrio entre os processos de formação das representações, da relação do produto com a comunicação e da influência social que atua na construção dos significados ${ }^{(15)}$.

A pesquisa ocorreu entre março e abril de 2017, no Hospital Regional do Município de Guanambi, Bahia, Brasil, único hospital de grande porte da microrregião na qual a cidade está localizada. A cidade é sede da microrregião de saúde e referência para outros 22 municípios.

Foram convidados a participar da pesquisa os profissionais de enfermagem (técnicos de enfermagem e enfermeiros) que trabalhavam nos setores Internamento, Emergência, Unidade de Terapia Intensiva (UTI) e Centro Cirúrgico (CC), após explicação dos objetivos da pesquisa. Adotaram-se os seguintes critérios de inclusão: profissionais que trabalham apenas em serviços noturno, já que esses profissionais trabalham em um ritmo diferente das suas funções biológicas, o que pode afetar a sua saúde biopsicossocial ${ }^{(11)}$; aqueles que tenham passado pelos três meses de experiência profissional e que não estivessem em gozo de férias ou afastado. Para os critérios de exclusão, delimitou-se: aqueles que possuíssem alguma indisponibilidade no trabalho no momento da coleta.

$\mathrm{O}$ estudo teve duas etapas. A amostra, na primeira etapa, constou de 70 profissionais de enfermagem, que se prontificaram em ser entrevistados. Na segunda etapa, apenas 23 tiveram interesse em participar, alegando falta de tempo.

Utilizaram-se dois instrumentos de coleta de dados: o primeiro instrumento, utilizado na primeira etapa, foi o teste de associação livre de palavras (TALP) ${ }^{(19)}$. Este continha, inicialmente, variáveis sobre dados de identificação dos participantes (categoria profissional, sexo, idade, tempo de formação, tempo de serviço, uso de equipamento de proteção individual, acidentes de trabalho). A aplicação do TALP corre naturalmente pela associação, livre e rapidamente, das palavras indutoras (estímulos) 
ditas pelo pesquisador, fazendo com que o participante diga outras palavras (respostas) ou palavras induzidas ${ }^{(19)}$. As palavras indutoras para que os participantes associassem foram: riscos ocupacionais, riscos biológicos. Tais estímulos produziram, por parte dos entrevistados, palavras e/ou expressões que vieram à sua mente no momento em que foram questionados.

A entrevista em profundidade ${ }^{(20)}$ contemplou o segundo instrumento de coleta de dados, contendo uma questão aberta para nortear: "Fale-me o que essas palavras (riscos ocupacionais, riscos biológicos) representam para o seu trabalho em seu dia a dia".

A coleta de informações ocorreu em pequenas salas alocadas nos setores do hospital, individualmente. Os achados foram gravados e transcritos na íntegra pelo pesquisador. A aplicação da TALP durou em média dez minutos para cada participante, enquanto as entrevistas tiveram um tempo médio de 30 a 40 minutos. Devido a pouca disponibilidade de tempo dos profissionais, não houve repetição das entrevistas.

Os dados coletados receberam análise de conteúdo ${ }^{(21)}$ das palavras evocadas por alvo de constelação e do conteúdo semântico das falas decorrentes das entrevistas, que, em seguida, foram trianguladas e transversalizadas com as evocações, sendo agrupadas a partir das similaridades semânticas para evitar a formação de redundâncias e torná-las com frequência significativa. Por fim, realizou-se a análise por aproximação semântica, de forma condensada, através do gráfico do alvo de constelação de palavras evocadas para cada estímulo(21), com o auxílio do Microsoft Power Point, versão 2010, em que as palavras com maiores frequências se encontraram organizadas no centro do alvo (círculos menores internos) e as com menores frequências, mas também importantes para a representação do grupo, nas áreas externas do gráfico (círculos maiores externos).

A pesquisa obedeceu aos princípios éticos da Resolução $n^{\circ} 466 / 2012^{(22)}$, sendo aprovada pelo Protocolo 2012036/2017 do Centro de Educação Superior de Guanambi (CESG). Todos assinaram o Termo de Consentimento Livre e Esclarecido e, para manter o anonimato dos participantes, receberam codinomes: para os técnicos de enfermagem, a sigla TEC sequenciada por um número (exemplo TEC. 01) e, por sua vez, os enfermeiros foram nomeados pela sigla ENF e um número (exemplo ENF. 01).

\section{RESULTADOS E DISCUSSÃO}

Serão apresentados a seguir os dados de identificação dos participantes e os dados oriundos da TALP triangulados com os discursos oriundos da entrevista em profundidade.

A população que constituiu o grupo de participantes era composta por 30 enfermeiros e 40 técnicos de enfermagem, que atuam em diferentes setores do hospital pesquisado. Sendo 48 profissionais do sexo feminino e 22 do sexo masculino, com faixa etária entre 20 anos a 60 anos. Quanto ao tempo de formação, cinco profissionais possuem de três meses a um ano; 17 possuem de um ano a cinco anos; 21, cinco anos a dez anos; e 27, acima de dez anos. Quando se refere ao tempo de serviço desses profissionais, 15 possuem de três meses a um ano, 12 profissionais possuem de um a cinco anos, 20 têm de cinco a dez anos e 23 acima de dez anos. Dentre a quantidade de profissionais entrevistados, 48 afirmaram que utilizam EPI em todos os procedimentos e 22 não utilizam. Além disso, 30 já sofreram acidente de trabalho e 40 disseram que nunca sofreram.

Os dados oriundos do TALP, evocadas pelos estímulos indutores, possibilitaram apreender as representações sociais dos profissionais entrevistados. Primeiramente, iniciou-se com a listagem das palavras evocadas para cada estímulo indutor. Em seguida, foram colocadas em grupos por classificação e incorporadas as palavras idênticas, ou próximas, em conteúdo semântico. Posteriormente, esse procedimento compôs o corpus de um total de 548 palavras, das quais 141 eram diferentes.

Logo em seguida, as palavras foram colocadas em ordem de maior repetição, ou seja, de frequência para cada estímulo, conforme apresentado nas Figuras 1 e 2. Ressalta-se que o ponto de corte para a frequência das palavras mais evocadas, ou seja, com maior ocorrência entre o grupo, foi de 05. Esse corte decorre das questões características das representações sociais, as quais são processadas dentro de um grupo e assim caracteriza aquilo que é comum e, portanto, a pertença do grupo. Um número menor que cinco indicaria apenas as impressões individuais, e esse não é o foco da teoria ${ }^{(19,23)}$.

A palavra acidentes surgiu, porventura, decorrente do contato com material perfurocortante e que, consequentemente, representa fontes de contaminação, adquirida por bactérias ou outro tipo de microorganismo. O estímulo foi associado também à segurança com o EPI. Essas evocações compõem a rede de significados, logo conformando as representações sociais. Além disso, a representação do risco ocupacional relacionado ao estresse contribuiu para compreender nuances que revelam o pertencimento desse grupo como dupla jornada, sobrecarga de trabalho e o trabalho noturno. Tais palavras são evidenciadas e explicadas nas falas abaixo:

\footnotetext{
"Nem sempre dá tempo usar os EPI. Eles são importantes, mas é uma correria muito grande nos atendimentos aqui, na emergência, e acaba que não dá nem tempo de pensar na contaminação, nas bactérias, nos vírus. ” (TEC. 07)

"A gente se preocupa com a falta de materiais, porque pode prejudicar a gente e adquirir alguma doença. Às vezes, faltam EPI e eles são importantes para a nossa segurança, não é?!” (ENF. 14)

"Para ter um salário melhor, precisamos de mais empregos, sabe?! A gente precisa complementar nossa renda. Às vezes, a gente tenta se manter ativa, mas a correria é tão grande que, às vezes, nem lembro de usar. Também a gente se irrita com algumas coisas que acontecem, é paciente falando, são médicos que não fazem direito a função deles." (ENF. 21)
} 
"Trabalhar a noite é diferente, porque a gente já chega cansada do outro serviço. E ainda tem que ficar acordada, dorme porque tem que vigiar os pacientes e dá o medicamento da madrugada também se tiver intercorrência. No dia a dia, fico estressada em casa, ou até aqui mesmo, com as pessoas chamando toda hora." (TEC. 17)

A Figura 1 apresenta as evocações com as maiores frequências para o estímulo riscos ocupacionais associadas pelos profissionais de enfermagem.

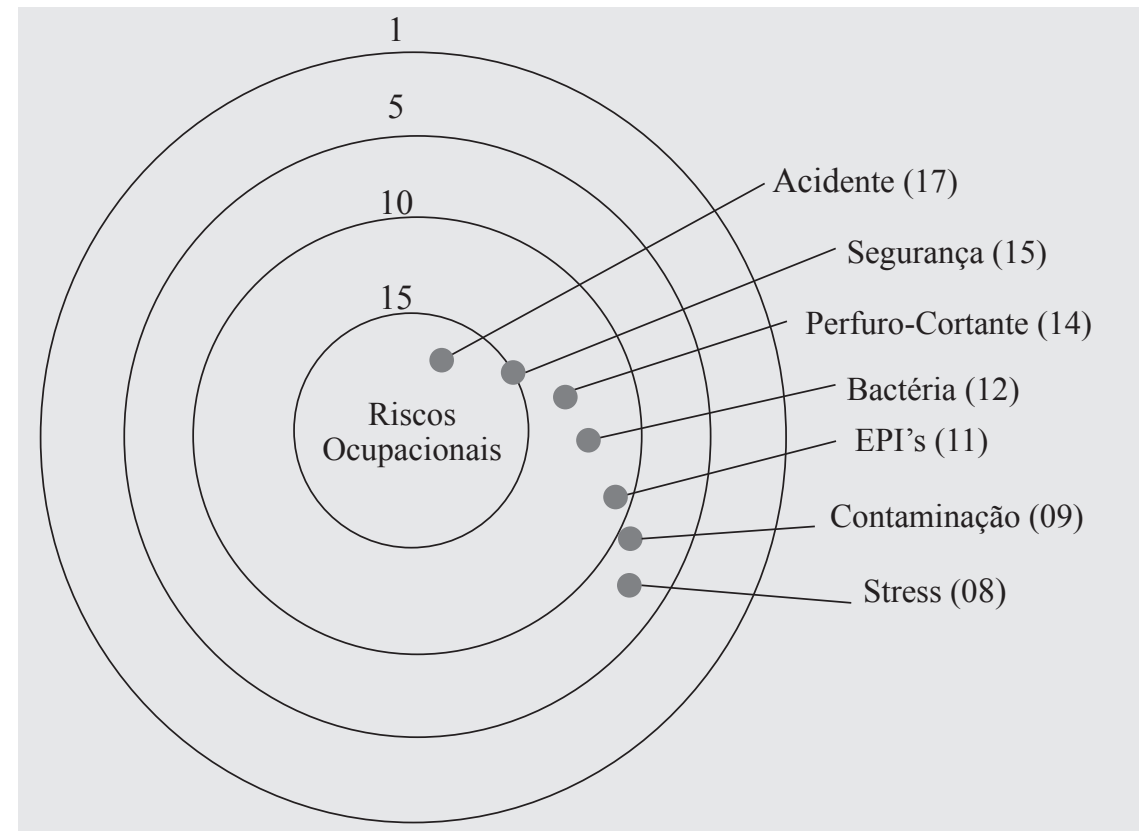

Fonte: Dados da pesquisa. EPIs: equipamento de proteção individual.

Figura 1 - Alvo de constelação de atributos do estímulo 1: "riscos ocupacionais". Guanambi, Bahia, Brasil, 2017.

A palavra segurança, evocada pelos profissionais com alta frequência, revela o quanto possuem conhecimento sobre o perigo que os riscos ocupacionais podem acarretar durante o seu processo de trabalho. Sabe-se que o risco de adoecimento ocorre pela quantidade de fatores ligados ao processo de trabalho, contudo, o EPI deve ser utilizado em todos os procedimentos que oferecem risco de acidente, a fim de minimizá- $\operatorname{los}^{(24)}$.

$\mathrm{O}$ risco ocupacional foi representado fortemente pela palavra acidente na presente pesquisa. Estudos apontam que, durante $\mathrm{o}$ desenvolvimento das atividades laborais, os profissionais de enfermagem ficam expostos a diferentes riscos que podem acarretar em acidentes. Salienta-se que os acidentes podem ocorrer de acordo com a duração da exposição ao risco ou da forma que o profissional desenvolve determinada atividade, e se o mesmo utiliza, ou não, equipamentos adequados ${ }^{(24,25)}$.

Em um estudo sobre as práticas de incentivo à cultura de segurança entre profissionais, apontou-se que a assistência segura, sem riscos ou agravos para o profissional, ou seja, a segurança do profissional deve ser finalidade da equipe de enfermagem, visto que o cuidado de enfermagem demanda atualização de conhecimentos e técnicas, destreza e experiência e conhecimento cientifico e técnico ${ }^{(26)}$.

O ambiente hospitalar, um dos locais de trabalho dos enfermeiros, por oferecer uma alta demanda de serviços a diversos grupos populacionais, é considerado uma grande área de risco, pois podem ocorrer diversos acidentes provocados por agentes biológicos, químicos, físicos, psicossociais e até mesmo decorrentes da forma de organização do trabalho ${ }^{(4)}$.

Em pesquisa realizada no ano de 2015 sobre as representações sociais com profissionais de enfermagem da atenção primária acerca dos riscos biológicos, verificou-se que eles representaram os riscos a partir das vivências envolvendo acidentes ocupacionais, sobretudo nas associações acidente-material e acidente-exposição. Portanto, os participantes demonstraram medo e preocupação com a exposição ao sangue e ao material contaminado por micro-organismos ${ }^{(27)}$.

A contaminação numa área hospitalar é caracterizada pelo contato direto com os fluídos potencialmente contaminados, quando entram em contato com a mucosa ou pele do profissional ${ }^{(28)}$. Desta forma, quando algum tipo de acidente ocorre, faz com que os profissionais tenham um misto de sensações negativas e representem sentimentos como medo, morte e preocupação ${ }^{(28)}$.

Em um estudo desenvolvido em um hospital público do Ceará, Brasil, com profissionais de enfermagem que sofreram acidente ocupacional com riscos biológicos, os autores levantaram os sentimentos dos profissionais diante dessa situação e perceberam representações de sentimentos como medo, desespero, ansiedade e preocupação em adquirir alguma doença ${ }^{(29)}$.

As representações sociais, processadas no sistema de cognição humana, refletem a vivência e a experiência individual diante de situações cotidianas, que pode ser comum com a de outras pessoas e, por isso, conformam os grupos de pertenças. A pertença 
é o sentimento de pertencer a um grupo com características em comum, as quais levam a percepção dos significados atribuídos aos fenômenos e dos comportamentos adotados e representados ${ }^{(30)}$.

O estresse, palavra evocada pelos profissionais participantes do presente estudo, é considerado como doença ocupacional. Durante a jornada de trabalho podem desenvolver momentos estressores decorrentes de sobrecarga de trabalho, mudança de turno ou trabalho noturno, barulhos e mudança de função ${ }^{(31)}$.

Em outra pesquisa, que visou refletir sobre as representações socais de enfermeiros de um hospital público de Natal, Rio Grande do Norte, Brasil, acerca do serviço e da sua relação com o estresse, foi evidenciado nas falas dos profissionais a associação com a sobrecarga de trabalho, com a desmotivação e a precarização das relações interpessoais ${ }^{(32)}$. Por sua vez, em outro estudo, também realizado com profissionais de enfermagem, sobre o estresse e as estratégias de enfrentamento, verificou-se que a maioria dos profissionais trabalhavam sob alta demanda psicológica e baixo controle no trabalho que executavam, o que interferia no relacionamento entre a coletividade devido ao baixo apoio social ter sido a maior consequência ${ }^{(33)}$.

Desta forma, as representações sociais, avaliadas em nível social, integram uma rede de significações oriundas do inconsciente, em que as experiências com os riscos no ambiente de trabalho conduzem a conformação das representações. Contudo, mesmo que os indivíduos pertencentes ao mesmo grupo possam ser bastante distintos em suas personalidades, eles se aproximam uns dos outros no que diz a respeito à estrutura básica de sua experiência social comum, de seu pensamento e de sua ação(34).

Assim, entende-se que as representações são uma maneira específica de compreender e comunicar o que é senso comum na sociedade e no grupo de pertença, cujo objetivo se ancora nas abstrações que o indivíduo e a coletividade dão a algum fenômeno a partir dos sentidos, da memória, dos significados, dos comportamentos e das percepções que reproduzam no seu cotidiano de forma significativa ${ }^{(15)}$.

No atual estudo realizado com profissionais de enfermagem do turno noturno, especificamente, as representações acerca dos riscos ocupacionais são reproduzidas pelo contato com os agravos que decorrem de fatores específicos do ambiente e do cotidiano de trabalho, e que colocam em risco a saúde desses profissionais e dos significados que dão a isto, dentre os quais, destacam-se: o tempo de serviço, a formação e a categoria profissional, e os estressores do serviço. O estímulo riscos biológicos esteve representado pelas evocações (apresentadas na Figura 02) sangue, bactéria, secreção, vírus que causam contaminação decorrente do contato com material perfurocortante, gerando perigo, pois mesmo que tenha o EPI, os profissionais podem sofrer acidente durante o desenvolvimento de algum procedimento.

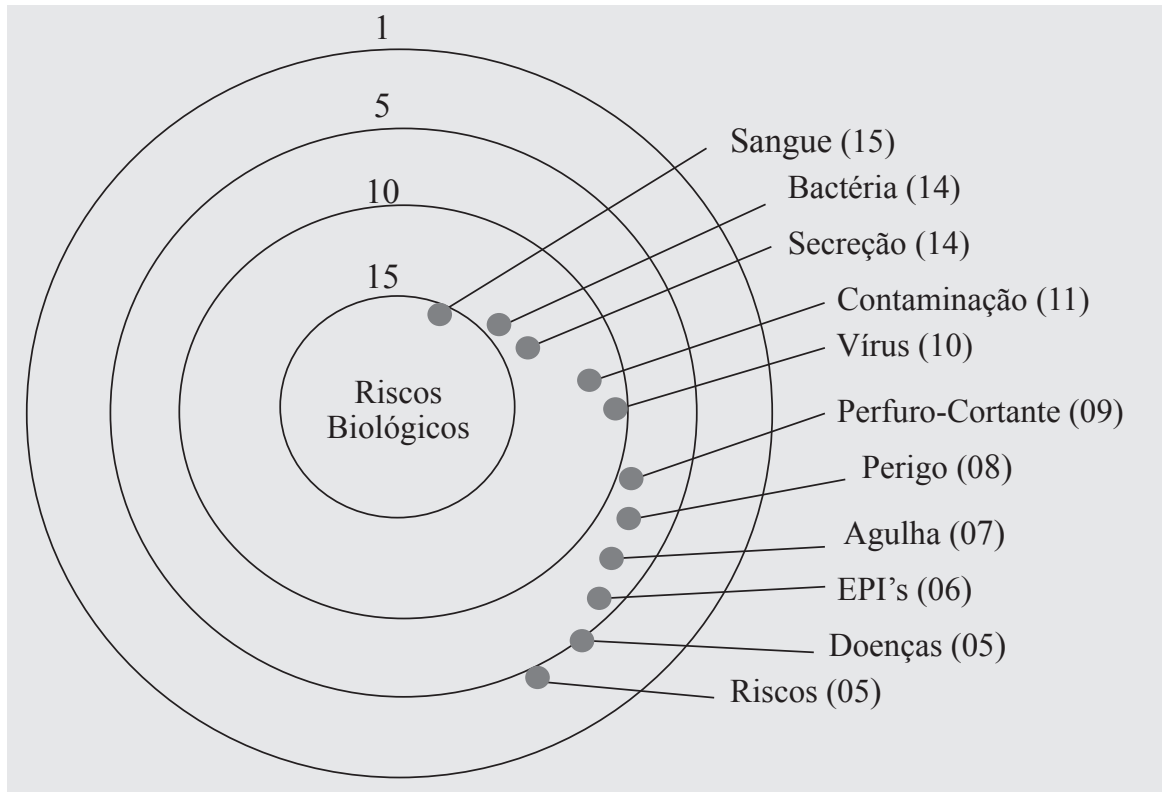

Fonte: Dados da pesquisa; EPIs: equipamento de proteção individual.

Figura 2 - Alvo de constelação de atributos do estímulo 2: "riscos biológicos". Guanambi, Bahia, Brasil, 2017.

A seguir, os discursos obtidos nas entrevistas em profundidade que se coadunam e explicam as evocações:

"[ ] Não é necessário usar EPI em todos os procedimentos, pois não é toda hora que a gente entra em contato com o paciente que apresente presença de risco[ ].” (TEC. 10)

"[ ] Nunca sofri acidentes até hoje, nunca adquiri uma doença no trabalho, tomo muito cuidado quando chego no paciente, por isso nem sempre uso os EPI[ ].” (TEC. 13)

“[ ] Trabalho há dez anos no serviço, muita gente se contaminou com vírus e bactérias e teve acidentes que envolveram sangue e escarro de paciente, graças a Deus eu nunca. Tenho muito cuidado em me furar com as agulhas ou me cortar com lâminas [ ]." (ENF. 07) 
"[ ] Sempre existe o perigo de ficar doente, de pegar doenças, infecções e ficar estressada por conta do tempo que temos para realizar os procedimentos [...].” (ENF. 01)

“ [ ] Já tive um colega que se contaminou com perfurocortante que tinha sangue e adquiriu HIV, por não usar EPI, por isso tento usar sempre [ ]." (TEC. 15)

Os riscos biológicos que estão presentes durante a jornada de trabalho dessa categoria podem ocasionar alguma doença ocupacional, sobretudo, doenças infectocontagiosas. Os profissionais entrevistados no presente estudo demonstram conhecê-las, mas não possuem dimensão do perigo considerando aos problemas com o uso do EPI.

A palavra de maior significância representada pelos profissionais para o estímulo "riscos biológicos" foi sangue, pois é o liquido com o qual os profissionais possuem maior contato dentro da área hospitalar. Por ser um agente biológico, o sangue oferece risco para a saúde do profissional, como adquirir doença com o vírus da imunodeficiência humana (HIV), hepatite B (HBV) e hepatite $\mathrm{C}(\mathrm{HCV})$, pois a transmissão dessas doenças ocorre através da exposição da pele ou mucosas ao sangue infectado ${ }^{(6)}$.

A baixa evocação da palavra EPI é preocupante, pois é uma barreira que as instituições empregatícias devem fornecer gratuitamente para prevenção de acidentes aos profissionais. Os profissionais omitem a utilização de EPI pela autoconfiança ou pela pressa na realização dos procedimentos. Desse modo, as RS não interferem nos conhecimentos ou conceitos dessas pessoas, vindo de um sistema de pensamentos que elaboram os valores e as noções acerca de algo, revelando nas práticas e nas condutas ${ }^{(34)}$.

Notou-se, em estudos realizados anteriormente, que uma das causas à exposição aos itens biológicos é o acidente e o possível adoecimento. Isto ocorre devido à resistência na utilização das precauções-padrão para prevenções ${ }^{(35,36)}$. Entretanto, o acidente com materiais biológicos não motiva a obrigatoriedade da utilização de EPI, mas os profissionais estão cientes que a conduta da utilização das precauções diminui os riscos de acidentes e, consequentemente, de contaminações ${ }^{(35,36)}$.

$\mathrm{O}$ uso de EPI deve obedecer às exigências dos procedimentos realizados para promover a segurança e diminuir os riscos envolvidos, para não interferir na execução correta do procedimento. A falta de uso de EPI pode resultar em danos para todos os envolvidos, como doenças ocupacionais, desordens emocionais e psicológicas, e problemas nas relações interpessoais, familiares e no trabalho ${ }^{(37)}$.

As RS no campo da saúde são originadas das opiniões trocadas e compartilhadas entre os profissionais, da produção dos comportamentos coletivos e das interações sociais, do modo como conduzem as práticas para a promoção da saúde e dos significados que dão ao processo saúde-doença ${ }^{(19)}$. Deste modo, os profissionais de enfermagem da presente pesquisa demonstraram, através das representações sociais, como enfrentam os problemas ocupacionais causadores de agravos, como a contaminação por material biológico, e a forma como se previnem ${ }^{(38)}$.

A palavra risco, evocada pelos profissionais no TALP no atual estudo, surge como significado de um grupo de diferentes causas de acidentes, podendo ser morte, danos à saúde ou lesão, aos quais estão susceptíveis dentro da área hospitalar. Tais representações sociais revelam o nível de avaliação social (do grupo) acerca de todo o significado envolvido nos riscos, o que determina a condição social no cotidiano de trabalho, condição que origina, caracteriza e justifica conceitos e pensamentos a partir das regras que eles próprios adotam para si e para o grupo no qual estão inseridos ${ }^{(15,34)}$.

Em pesquisa realizada em um hospital privado de médio porte no estado do Piauí, Brasil, sobre as representações sociais elaboradas por técnicos de enfermagem acerca dos acidentes com materiais perfurocortantes, eles revelaram, a partir de seus inconscientes, que são as condutas adotadas diariamente pelos profissionais que condicionam os acidentes e que o medo de contrair algum microrganismo, como o HIV, os levam a pensar antes de fazer algum procedimento e, ainda assim, não é suficiente para evitar a exposição, o que revela medo e preocupação ${ }^{(39)}$.

Salienta-se que a classe da enfermagem é a de maior representatividade dentro da área hospitalar quando comparado a outras classes assistenciais $^{(35,38)}$. Este dado também pode ser corroborado pela pesquisa desenvolvida em um hospital filantrópico de nível terciário do interior de São Paulo, Brasil, quando os profissionais apontaram que é no ambiente do hospital, sobretudo nas áreas de internamento, que eles possuem maior exposição com material biológico contaminado ${ }^{(40)}$. Outros estudos já realizados mostraram que os profissionais de enfermagem são os que possuem um grau maior de perigo de vida durante o trabalho, uma vez que concentram os seus cuidados na melhoria da saúde e no apoio aos pacientes em setores de internamento, esquecendo-se do seu cuidado individual pela exposição aos riscos relacionados à prática de suas condutas ${ }^{(6,27,35,38)}$.

O ambiente no qual os profissionais de saúde estão inseridos os deixam expostos aos riscos ocupacionais, sobretudo riscos biológicos, e a negligência no uso de EPI os deixam vulneráveis à contaminação com materiais biológicos. Por isso, os gestores dos serviços de saúde devem promover espaços para atividades de educação em saúde com profissionais, no intuito de evitar, ou minimizar, práticas inadequadas, rotineiras e viciosas, e potencializar o uso dos equipamentos de proteção individual( ${ }^{(25,39)}$.

No âmbito da promoção à saúde do trabalhador, as RS dos profissionais de enfermagem do turno noturno sobre os riscos de acidente de trabalho possibilitam a reflexão de que o estímulo às práticas de prevenção e orientação/capacitação são essenciais para a prevenção de agravos ocupacionais, sobretudo daqueles decorrentes dos que envolvem os acidentes de trabalho com materiais biológicos.

Este presente estudo teve sua limitação no quantitativo de profissionais, por ter ocorrido em um hospital público de grande porte de uma microrregião de saúde no Nordeste do Brasil, o que impossibilita fazer generalizações, uma vez que o grupo possui 
pessoas com perfis e condições de vida distintas de outras localidades, que variam conforme a cultura e a localidade. Entretanto, apesar dessa limitação, há relevância no fato de que algumas representações se coadunam com aquelas apresentadas em estudos realizados em outras regiões, além de revelar as singularidades reveladas nas representações, como a autoconfiança, além da incapacidade em não reconhecer a própria insegurança para a prática laboral.

\section{CONSIDERAÇÕES FINAIS}

Os riscos ocupacionais e biológicos, que foram evidenciados por meio das representações sociais dos profissionais de enfermagem, estão relacionados aos fatores de risco para os acidentes de trabalho. Destarte, os resultados mostraram, a partir da apreensão e das reflexões sobre as representações sociais, que a equipe de enfermagem se identifica com fatores de risco, muitas vezes emergidos durante o desempenho das atividades ocupacionais do cotidiano hospitalar.

Os resultados demonstraram que os profissionais de enfermagem sabem da existência dos riscos para os acidentes de trabalho, como os riscos ocupacionais e os riscos biológicos, reconhecendo o perigo, mas com o outro, não consigo, o que sugere uma dificuldade em distinguir a própria insegurança.

As representações acerca dos riscos biológicos foram reproduzidas pelo contato com os agravos que decorrem de fatores específicos do ambiente e do cotidiano de trabalho, e que colocam em risco a saúde desses profissionais, refletindo nos significados que compõem as representações sobre o objeto aqui evidenciado.

A partir desse conhecimento apreendido, profissionais de saúde, especificamente os que compõem a categoria da enfermagem, podem refletir sobre as RS elaboradas e propor caminhos para estratégias preventivas e de intervenção, como atividades de educação profissional permanente para redução dos acidentes de trabalho, a partir da minimização dos riscos ocupacionais e biológicos, tendo em vista a necessidade em repensar a biossegurança no ambiente hospitalar.

\section{CONFLITOS DE INTERESSES}

Esse estudo não apresenta conflitos de interesse.

\section{REFERÊNCIAS}

1. Neves ZCP, Tiplle AFV, Mendonça KM, Souza ACS, Pereira MS. Legislações e recomendações brasileiras relacionadas à saúde e segurança ocupacional dos trabalhadores da saúde. Rev Eletrônica Enferm. 2017;19:1-8.

2. Contreras GT, Torrealba BJ, Salinas MF. Enfermedades respiratorias laborales en Chile. Ley 16.744. Rev Chil Enferm Respir. 2014;30(1):27-34.

3. Miranda FMA, Cruz EDA, Félix JCV, Kalinke LP, Mantovani MF, Sarquis LMM. Perfil dos trabalhadores brasileiros vítimas de acidente de trabalho com fluidos biológicos. Rev Bras Enferm. 2017;70(5):1117-24.

4. Bezerra AMF, Bezerra KKS, Bezerra WKT, Athayde ACR, Vieira AL. Riscos ocupacionais e acidentes de trabalho em profissionais de enfermagem no ambiente hospitalar. Rev Bras Educ Saúde. 2015;5(2):1-7.

5. Neittzel RL, Long RN, Sun K, Sayler S, Von Thaden TL. Injury risk and noise exposure in firefighter training operations. Ann Occup Hyg. 2016;60(4):405-20.

6. Oliveira EC, Ponte MAC, Dias MAS, Silva ASR, Torres ARA, Ferreira VES. Análise epidemiológica de acidentes de trabalho com exposição a material biológico entre profissionais de enfermagem. Sanare (Sobral, Online). 2015 [acesso em 2016 Dez 2];14(01):27-32. Disponível em: https://sanare.emnuvens.com.br/sanare/article/view/603/320

7. Tinubu BMS, Mbada CE, Oyeyemi AL, Fabunmi AA. Work-related musculoskeletal disorders among nurses in Ibadan, South-west Nigeria: a cross-sectional survey. BMC Musculoskelet Disord. 2016;11:12.

8. Wang Y, Xie J, Fang F, Wu S, Wang H, Zhang X, et al. The prevalence of primary headache disorders and their associated factors among nursing staff in North China. J Headache Pain. 2015;16(4):1-7.

9. Silva FFA, Farias HNCF, Costa RHS, Souza NL, Carvalho JBL, Silva RAS. Riscos de acidentes com materiais perfurocortantes no setor de urgência de um hospital público. J Res Fundam Care Online. 2016;8(4):5074-9.

10. Carvalho DC, Rocha JC, Gimenes MCA, Santos EC, Valim MD. Acidentes de trabalho com material biológico na equipe de enfermagem de um hospital do Centro-Oeste brasileiro. Esc Anna Nery Rev Enferm. 2018;22(1):e20170140.

11. Lee ML, Howard ME, Horrey WJ, Liang Y, Anderson C, Shreeve MS. High risk of near-crash driving events following night-shift work. PNAS. 2016; 113(1):176-81. 
12. Brasil. Lei $\mathrm{N}^{\circ} 8.213$, de 24 de julho de 1991. Dispõe sobre Acidente do trabalho é o que ocorre pelo exercício do trabalho a serviço de empresa ou de empregador doméstico ou pelo exercício do trabalho dos segurados referidos [acesso em 2016 Dez 2]. Disponível em: http://www.planalto.gov.br/ccivil_03/leis/18213compilado.htm

13. Brasil. Ministério do Trabalho. Portaria $n^{\circ} 3.214$, de 08 de junho de 1978. Dispõe sobre NR 6-Equipamento de Proteção Individual - EPI [acesso em 2016 Dez 2]. Disponível em: http://www.camara.gov.br/sileg/integras/839945.pdf

14. Brasil. Ministério do Trabalho. Portaria n. ${ }^{\circ} 485$, de 11 de novembro de 2005. Dispõe sobre NR 32 - Segurança e Saúde no Trabalho em Serviços de Saúde [acesso em 2016 Dez 2]. Disponível em: http://www.trtsp.jus.br/geral/tribunal2/ORGAOS/ MTE/Portaria/P485_05.html

15. Moscovici S. Representações Sociais: Investigações em Psicologia Social. Petropólis: Vozez; 2012.

16. Lopes Joaquim F, Cavalcanti Valente GS. A relação da biossegurança com o custo-efetividade nas hospitalizações: nexos com a educação permanente. Enferm Glob. 2013;30(1):355-69.

17. Van der Molen HF, den Herder A, Warning J, Frings-Dresen MHW. National evaluation of strategies to reduce safety violations for working from heights in construction companies: results from a randomized controlled trial. BMC Public Health. 2016; 16(19):1-8.

18. Minayo MCS. O desafio do conhecimento. 13ª ed. São Paulo: Editora Hucitec; 2013.

19. Coutinho MPL. Representações sociais: abordagem interdisciplinar. Paraíba: Ed Universitária/UFPB; 2003.

20. Gaskell G. Entrevistas individuais e grupais. In: Bauer MW, Gaskell G, organizadores. Pesquisa qualitativa com texto, imagem e som: um manual prático. Petropólis: Vozes; 2002. p. 64-89.

21. Bardin L. Análise de conteúdo. Lisboa: Edições 70; 2010.

22. Conselho Nacional de Saúde (BR). Resolução n o 466, de 12 de dezembro de 2012 [acesso em 2016 Dez 2]. Disponível em: http://conselho.saude.gov.br/resolucoes/2012/reso466.pdf

23. Jovchelovitch S. Vivendo a vida com os outros: intersubjetividade, espaço público e representações sociais. In: Guareschi PA, Jovchelovitch S. Textos em representações sociais. Petrópolis: Vozes; 2012. p. 63-88.

24. Martins JT, Bobroff MCC, Andrade AN, Menezes GDO. Equipe de enfermagem de emergência: riscos ocupacionais e medidas de autoproteção. Rev Enferm UERJ. 2014;22(3):334-40.

25. Facchin LT, Gir E, Pazin-Filho A, Hayashida M, Canini SRMS. under-reporting of accidents involving biological material by nursing professionals at a brazilian emergency hospital. Int J Occup Saf Ergon. 2013;19(4):623-9.

26. Barros AA, Oliveira RM, Pinheiro AC, Leitão IMTA, Vale AP, Silva LMS. Práticas de incentivo à cultura de segurança por lideranças de enfermagem segundo enfermeiros assistenciais. Rev Enferm UFPE Online. 2014;8(12):4330-6.

27. Sousa AFL, Queiroz AAFLN, Oliveira LB, Moura MEB, Batista OMA, Andrade D. Representações sociais da Enfermagem sobre biossegurança: saúde ocupacional e o cuidar prevencionista. Rev Bras Enferm. 2016;69(5):864-71.

28. Souza FT, García MC, Rangel PPS, Rocha PK. Percepção da enfermagem sobre os fatores de risco que envolvem a segurança do paciente pediátrico. Rev Enferm UFSM. 2014;4(1):152-62.

29. Araújo TM, Caetano JÁ, Barros LM, Lima ACF, Costa RM, Monteiro VA. Acidentes de trabalho com exposição a material biológico entre os profissionais de Enfermagem. Referência. 2012;7(3):7-14.

30. Wagner W. Descrição, explicação e método na pesquisa das representações sociais. In: Guareschi PA, Jovchelovitch S. Textos em representações sociais. Petrópolis: Vozes; 2012. p. 149-86.

31. Oliveira RJ, Cunha T. Estresse do profissional de saúde no ambiente de trabalho: causas e consequências. Cad Saúde Desenv. 2014;3(2):78-93.

32. Oliveira JDS, Alchieri JC, Pessoa JM Júnior, Miranda FAN, Almeida MG. Representações sociais de enfermeiros sobre o estresse laboral em um serviço de urgência. Rev Esc Enferm USP. 2013;47(4):984-9.

33. Teixeira CAB, Gherardi-Donato ECS, Pereira SS, Cardoso L, Reisdorfer E. Estresse ocupacional e estratégias de enfrentamento entre profissionais de enfermagem em ambiente hospitalar. Enferm Glob. 2016; 44(3):299-309. 
34. Guareschi PA, Jovchelovitch S. Textos em representações sociais. Petrópolis: Vozes; 2012.

35. Ruas EFG, Santos LS, Barbosa DA, Belasco AGS, Bettencourt ARC. Acidentes ocupacionais com materiais perfuro cortantes em hospitais de Montes Claros-MG. REME Rev Min Enferm. 2012;16(3):437-43.

36. Moraes KKO, Almeida LF, Silva LPM, Santos MLGF, Silva ES, Jesus CS. Exposição da equipe de enfermagem aos riscos biológicos em unidade de terapia intensiva: revisão integrativa. Rev Inova Saúde. 2016;5(2):163-84.

37. Ferreira LA, Peixoto CA, Paiva L, Silva QCG, Rezende MP, Barbosa MH. Adesão às precauções padrão em um hospital de ensino. Rev Bras Enferm. 2017;70(1):96-103.

38. Santos JLG, Vieira M, Assuiti LFC, Gomes D, Meirelles BHS, Santos SMA. Risco e vulnerabilidade nas práticas dos profissionais de saúde. Rev Gaúch Enferm. 2012;33(2):205-12.

39. Lubenow JAM, Moura MEB, Nunes BMVT, Figueiredo MLF, Sales LC. Representações sociais dos acidentes com materiais perfurocortantes. Rev Latinoam Enferm. 2012;20(6):1176-1185.

40. Negrinho NBS, Malaguti-Toffano SE, Reis RK, Pereira FMV, Gir E. Fatores associados à exposição ocupacional com material biológico entre profissionais de enfermagem. Rev Bras Enferm. 2017;70(1):133-8.

\section{Endereço para correspondência:}

Pablo Luiz Santos Couto

Centro de Ensino Superior de Guanambi - CESG

Av. Pedro Felipe Duarte, 4911

Bairro: São Sebastião

CEP: 46430-000 - Guanambi - BA - Brasil

E-mail: pabloluizsc@hotmail.com 